\title{
El Saint Domingue que conoció René Dupé
}

\section{M. ${ }^{\text {a }}$ MAGDALENA GUERRERO CANO}

Dispuestos a abordar el tema de América en el siglo XVIII, no podemos olvidar la documentación depositada en los Archivos Nacionales de Paris. Como consecuencia del auge francés en el mundo, el país galo se había posesionado de distintas parcelas del solar americano. El grupo de papeles que manó su administración y gobierno quedó depositado en la sección histórica de estos Archivos, en su apartado de "Marina y Colonias". De ahí, que en este volumen documental encontremos abundantes noticias del Saint Domingue francés hasta su independencia -1804 y de los primeros años del Haití actual.

Esta documentación puede recoger desde una descripción de las Antillas, presentandolas como posible campo de expansión del comercio francés, hasta la carta dél algún colono que cuenta las experiencias vividas. Pero en su mayor paarte es una documentación protocolaria y burocratizada. Entre las fuentes históricas hay abundantes actas notariales que recogen testamentos, escrituras de compra-venta, constitución de sociedades, resoluciones de pleítos comerciales, etc. También encontramos legislación sobre libertad de comercio, tratados internacionales sobre el tema, relaciones estadísticas que hacen referencia al comercio mantenido con las distintas islas caribeñas o con Estados Unidos; o los distintos colonos franceses en Saint Domingue que se relacionan comercialmente con la Cámara de Comercio de Nantes y que tenían derecho a ciertas prerrogativas.

Queriendonos centrar en el Saint Domingue de los años inmediatos a la Revolución Francesa, hemos acudido a esta documentación -sobre todo la de "declaración de herederos"- que aunque normatizada, nos da noticias de como el 1789 francés atañe a la sociedad de la isla.

Sabemos que desde mediados del siglo XVI, los bucaneros y filibusteros (1) de la isla de la Tortuga pasaban temporalmente a La Española en busca de alimentos, principalmente caza de ganado salvaje, sobre todo cerdos. Adaptandose con el tiempo a una vida más sedentaria, cultivaban la tierra, elaboraban los productos que necesitaban y fundaban ciudades como la del Cabo Francés (1670), y actualmente Haitiano.

Para tales trabajos necesitaron mano de obra, que les prestaron los negros traídos de Africa, como esclavos. En un primer momento según derecho exclusi-

(1) El apelativo de bucanero viene de "bucan" que era el lugar donde ahumaban carne para conservarla y filibusteros de los ligeros barcos o "fly boats" en que navegaban. 
vo y muy lucrativo de altos personajes de la Corte, y posteriormente por los mismos colonos.

Esta población -toda de origen foráneo- fue adquiriendo en la parte occidental de la isla -francesa desde el tratado de Ryswick (1697)- unas características peculiares y típicas de la nueva sociedad que estaba apareciendo. También hacían acto de presencia las rivalidades y tensiones que se daban en grupos más amplios.

En la base y como sector marginado estaban los esclavos, dedicados a los trabajos de cultivo y fabricación industrial. Su vida se desarrollaba en precarias condiciones. También había esclavos domésticos que eran sirvientes, cocineros, cocheros y que recibían mejor trato que los anteriores. Ambos podian ser "bossales o dandas"; nombre con el que se distinguían a los llegac os de Africa; y "criollos" o que llevaban más de una generación en la isla. Segúri el censo de 1791, en Saint Domingue había medio millón de esclavos (2).

Sobre ellos los "libertos" que podían serlo desde varias generaciones, o haber conseguido la manumisión por compra o por ser muy allegados a un blanco que les concedia la libertad, como podía ser en el caso de extrema fidelidad o las concubinas. Se equiparaban en algunos aspectos a los mulatos o mestizos, en su mayor parte hijos ilegítimos de blanco y negra. A éstos se les reconocían ciertas prerrogativas, ya que recibían alguna educación; incluso algunos eran enviados a Paris con tal fin. Pero no eran aceptados como iguales ni por los blancos, ni por los negros, a pesar de ser un grupo social en claro aumento.

El reconocimiento de esta gente de color-libre en Saint Domingue, tiene su origen en el Código Negro promulgado por Luis XIV en 1685. Su artículo 59 especificaba que

"...cuando un esclavo obtenía su libertad, ya fuera mediante compra en efectivo o como concesión de su amo o padre blanco, quedaba considerado como un ciudadano francés, con todos los derechos inherentes a la calidad de tal. Podía comprar tierras, disponer de su riqueza a su antojo, prestar testimonio en juicios legales (aún contra los blancos), casarse como le plugiera, votar, portar armas, viajar por donde lo deseare, abrazar cualquier carrera y poseer esclavos o liberarlos" (3).

Sin duda ni el Rey ni sus ministros imaginaban que por este artículo, muchos descendientes de esclavos conseguirían la ciudadanía francesa, y cierto relieve social, sustentado en una base de dasahogada economía y esmerada cultura. De forma que con el tiempo y superadas las leyes discriminatorias que aparecieron en la segunda mitad del siglo XVIII, esta clase pretendería mediante matrimonios, aclarar cada vez más su color; escalar más altos niveles sociales y acabaría despertando la envidia de los blancos de clase inferior.

Según algunos historiadores, para 1791 poseían la tercera parte de toda la tierra de la colonia y la cuarta parte de los esclavos, aunque otros opinan que era

(2) Este censo lo conocemos a través de LEYBURN, James G.: El pueblo baitiano. Sociedad Dominicana de Bibliófilos. Santo Domingo, R.D. 1986. pág. 27.

(3) Ibídem, págs. 28-29. 
sólo un quinto del total de la riqueza, lo que poseían (4). Aún así, buen motivo para despertar los celos de otras clases más necesitadas, aunque de blancos.

El censo de 1791 arroja el número de 28.000 gentes de color-libres (5).

Por último estaban lós blancos, divididos en "pequeños blancos" que desempeñaban profesiones como artesanos, boticarios, barberos, etc. y que mostraban su descontento y envidia por el grupo de los mulatos y libertos, cada vez más próspero; y los "grandes blancos" que eran dueños de haciendas o "habitaciones", militares de graduación o altos funcionarios civiles, que solian llevar una vida de opulencia. En el censo de 1791 aparecen 36.000 blancos (6).

En esta sociedad era lógico que aparecieran enfrentamientos entre las distintas castas; agravados porque en menos de un siglo Saint Domingue se había convertido en la colonia más rica de Francia y era la primera productora mundial de azúcar -en lo que desplazó a Jamaica- además de producir almíbar, algodón, índigo, cacao, caoba, campeche y café por el que Europa manifestó un gusto especial. Todo ello contribuyó a que en la época de esplendor de la colonia se planificaran y construyeran caminos, se hicieran importantes obras de irigación y se levantaran suntuosas mansiones para domicilio de los colonos blancos.

"Para la madre patria, este pequeño trozo de tierra tropical fue asimismo provechoso durante los últimos días del reinado de los Borbones. Ni Martinica ni Guadalupe podían comparársele en valor. En 1789 cerca de dos tercios de los intereses comerciales extranjeros de Francia se hallaban concentrados en Santo Domingo; sus exportaciones e importaciones combinadas eran valuadas en más de ciento cuarenta millones de dólares; su azúcar, café, añil y algodón abastecían el mercado metropolitano y empleaban en los años de prosperidad más de setecientos navíos oceánicos, con más de ochenta mil marineros" (7).

Esta es la singular sociedad y peculiar ambiente que vamos a encontrar como marco para nuestro trabajo.

Casi todos los dosieres que hemos visto de "declaración de herederos", son de las clase más alta de la sociedad, es decir del grupo de los "grandes blancos" - cosa lógica porque serían los que tendrían propiedades que podrían dejar en herencia-, que en su mayor parte tuvieron su "habitación" en la zona del Cabo Francés.

"la mayor parte de la mejor tierra del país se halla en las escasas planicies que flanquean las montañas en la proximidad de las costas, o se extien-

(4) Ibídem, págs. 30-31.

(5) Ibídem, pág. 28.

(6) Ibídem, pág. 27. Otras cifras de fechas muy cercanas a 1791, se aproximan mucho a estas. Según MOREAU DE SAINT-MERY, L.E., la población total dera de 519.000 almas; de las que 40.000 eran blancos, 28.000 gentes de color libres y 452.000 esclavos.

Description topograpbique, physique, civile, politique et bistorique de la partie française de l'ile Saint-Domingue. Filadelfia, 1797. vol. I, pág. 285;

(7) LACROIX, Pamphile de: Memoirs peur servir a l'bistoire de la revolution de Saint Domingue. Paris, 1820. vol. II, pág. 277. 
den como cuñas en las regiones montañosas. En el nordeste, detras de CapHaïtien, se halla la Llanura del Norte; aquí estaban situadas en los tiempos coloniales las más florecientes plantaciones de Francia, y las residencias palaciegas, y vivían los esclavos que, en 1791, comenzaron la insurrección que en definitiva dió por resultado la independencia de Haití" (8)

y que se mantenían en contacto con Francia a través de la Cámara de Comercio de Nantes.

Habían llegado como colonos en la segunda mitad del XVIII, adquiriendo pleno poder a finales de siglo, en los años de la Revolución francesa. He aquí las causas de que los hayamos estudiado en general, y de que contemplemos más detenidamente - a título de ejemplo- el crítico y simbólico caso de René Dupé.

El volumen documental que existe en los Archivos Nacionales no nos puede servir de guía para conocer el número total de emigrados, porque sabemos que en muchos casos era un viaje de ida y vuelta. Muchos franceses atendían negocios en ambas orillas del Atlantico; o bien tenían una gran propiedad en Saint Domingue en la que pasaban algunas temporadas y otras las pasaban en Paris, haciendo ostentación de la riqueza que habían podido acumular gracias a los esclavos que trabajaban las propiedades que habían dejado en la isla.

"Una "habitación" colonial se parecía a un pequeño pueblo. La casa del colono era casa siempre construida sobre una planicie, desde la cual se podía dominar toda la extensión de la "habitación". Una escalinata doble daba acceso al cuerpo de la casa principal, una gran construcción cuadrada, dividada en su interior por tabiques, y provista, en el contorno exterior, de barandas abiertas. Una alameda conducía allí, cerrada al gran camino por una puerta monumental y bordeada por una doble hilera de árboles, naranjos, limones, quenepos, mangos o tcha-tcha (albizaia lebbeck), cuyas perfumadas flores embalsamaban el aire. A derecha y a izquiera había otras construcciones, tiendas, depósitos, o simples chalets que servían de alojamiento a los huéspedes (9).

Este lujo tenía su contrapunto en el resto de la hacienda o "habitación".

"Más allá, en medio de una sabana, se erguían a igual distancia unas de otras, las cabañas de los esclavos, pintadas de cal y cubiertas de hojas de caña de azúcar. de plátano o de palma. Cada una tenía tres puertas y alojaba a tres familias. Cerca de la cabaña había un recinto habilitado donde el esclavo ponía los dos o tres cerdos que le eran permitido criar. Frente a la cabaña y a su alrededor, los negritos desnudos jugaban y se tendían en el lodo, confundiendose entre los animales. De lejos, se fijaba la mirada sobre una serie de construcciones cubiertas de tejas y coronadas de altas chimeneas de ladrillos rojos; éstas eran las "usinas" que comprendían algunos molinos, ingenio, destilería, procesadoras del índigo, etc. Entre el patio y los jardines, un largo

(8) LEYBURN, James G.: El pueblo baitiano. pág. 23.

(9) Ibídem, pág. 24. 
acueducto, sostenido por pilares de piedra de sillería, conducía al molino el agua que descendía de las montañas cercanas. En el horizonte se desplegaba hasta perderse de vista el mar inmenso de cañaverales, cafetales, cacaotales, algodoneros o platanares" (10).

De manera que en la Francia de la época se hizo popular la frase: "rico como un criollo".

En muchas ocasiones era un hombre solo él que emigraba, con el fin de amasarl una fortuna y volver a Francia, pero solía pasar que se quedaba para siempre en la isla, en la que o bien tomaba una esclava por concubina, con la que tenía hijos, o bien formaba una familia que no perdía su caracter francés e incluso pretemdía introducir refinamientos europeos en la ciudad del Cabo.

"...capital de la colonia, el Cap era la ciudad más rica, aquella donde la vida era más atrayente y más animada. A causa de su opulencia y de sus atracciones diversas, los colonos la llamabam el París de Saint Domingue. sus calles, demasiado estrechas, estaban bien mantenidas. Arboles magníficos sombreaban las plazas públicas, cada una de las cuales estaba adornada por una fuente monumental. el Paseo Villeverd, cerca de la barriére Bouteilla, era el preferido por los capois (habitantes del Cabo) porque se estaba seguro de encontrar allí a las más elegantes de la ciudad en sus más bellos atuendos. Por la noche se iba al teatro a aplaudir a los actores de renombre" (11).

Aparecen en la documentación abundantes noticias de manumisión de alguna mujer o muchachos de color, que supuestamente era la mujer y los hijos del francés. En estos casos los que heredaban eran los parientes legales más próximos -hermanos, sobrinos, primos, etc-que se habían quedado en la metrópoli. También nos encontramos casos en los que el colono ha formado una sociedad con algún amigo o pariente en Francia, frecuentemente en Nantes, como el caso de la "Compañía Watín-Chaumanseau-Lelong" (12) que mantienen relaciones epistolares y van rindiendo cuentas de la marcha del negocio en el que han invertido el dinero y cuyas ganancias han de repartir.

Un grupo de documentos interesantes para el historiador por la secuencia de noticias que aporta, aparece cuando se da la muerte de un colono sin haber hecho testamento y hay que hacer "declaración de herederos", o cuando se disuelve una sociedad y cada miembro recibe su parte correspondiente.

Era lógico que a finales del siglo XVIII, en que suponían tanto las distancias y las comunicaciones eran tan dificultosas, aparecieran pretendientes falsos para la fortuna que quedaba sin heredero inmediato. Más cuando el posible afortunado era un pariente colateral que vivía en Francia y que llevaba años sin recibir noticias del finado. A todo esto se unían los conflictivos años por los que estaba pasando Francia ten más de una ocasión nos encontramos con un difunto que ha

(10) BELlegarde, Dantes: La nación haitiana. Sociedad Dominicana de Bibliófilos. Santo Domingo, R.D. 1984 . pág. 79.

(11) Ibídem, pág. 83.

(12) Archivos Nacionales de París. Marina y Colonias. CC9c-10. 
sido "victime du regne de la terreur"- y por los que pasaría Saint Domingue a raíz de su independencia. No nos extraña que algunas herencias se reclamaran pasados cincuenta años, aunque lo normal es que cuando se trata de herederos directos, pero en distinto continente, toda la gestión se realizara en poco más de un año, dado que había que levantar actas ante notario, tanto en Francia, como en Saint Domingue; donde en la ciudad de El Cabo se hicieron famosos los notarios Geánty y Grimperal. Las cantidades de dinero que se barajaban suelen aparecer en libras tornesas, y en el mismo documento su equivalente en francos.

De hecho en los documentos consultados, todos los herederos son de color blanco, están en Francia y el difunto ha muerto sin testar. De ahí que hubiera que hacer "declaración de herederos"; documentos que nosotros ahora consultamos.

Cuando el enfrentamiento entre blancos y negros estaba llegando a sus extremos, es cuando estalla en Francia la Revolución. Ambos bandos creyeron llegado el tiempo de sus venturas, los blancos porque podrían gobernar la colonia a su antojo, sin ningún tipo de cortapisas. Los negros pensaron que podrían ejercer como ciudadanos franceses de pleno derecho, según se estipulaba en la "Declaración de los derechos del hombre".

Los acontecimientos de la metrópoli tuvieron claro eco en la colonia y los "grandes blancos" presionaron para obtener lo que ellos creían ya adquirido -el control de la colonia-, de forma que llamaron la atención de Paris sobre lo que estaba pasando en la isla, y sobre los movimientos de emancipación que ya habían aparecido como eran "Los amigos de los Negros".

Pero la Asamblea Nacional dictó unas medidas ambiguas, con las que todos se sintieron primero contentos y después defraudados. A continuación, en mayo de 1791, decretó que las Asambleas coloniales debían admitir a los hombres de color, hijos de padres libres. Ante esto, la reacción en Saint Domingue fue tan violenta que el Gobernador tuvo que suspender inmediatamente tal decreto; agravandose la crisis entre ambos sectores.

Los comisionados franceses Roume, Mirbeck y Saint-Legar no pudieron calmar la situación y fracasaron; siendo sustituidos por Santhonax, Polveret y Ailhaud que impusieron medidas favorables a los esclavos. En consecuencia los colonos blancos mostraron su descontento y gestionaron continuos complots.

Hubo levantamientos en Jacmel, en los Cayos y en Puerto Principe que fue bombardeado en abril de 1793. En la ciudad del Cabo se llegó a serios combates entre los colonos dirigidos por el Gobernador Galbaud y el grupo de negros y mulatos libres dirigidos por Santhonax, quien consiguió el auxilio de los esclavos a cambio de la promesa de libertad.

En el trancurso de estos sucesos se incendia la ciudad del Cabo y el grupo de comerciantes, como medida de urgencia, nombra a René Dupé (13), su delegado para que se dirija a la escuadra francesa y ruegue al general Galbaud que ordene a las fuerzas confiadas a sus ordenes, que desciendan a tierra y protejan la ciudad.

Pero éste, por diversos motivos entre los que estaban las desavenencias con los comisionados Santhonax y Polvéret, rehusó dar las ordenes que le demandaban y mandó dirigir la escuadra, con el ejército a bordo, hacía Nueva Inglaterra; dando tiempo para que los insurgentes ocuparan la ciudad.

(13) Ibídem. 
En uno de los barcos iba Dupé que no había podido obtener permiso para descender y, posteriormente, rendir cuentas a los que le habían enviado; tampoco para salvar, al menos, sus libros y papeles. Fue transportado a "Neuyoll", y murió antes de que terminara el año sin haber posido asegurarse de si sus cosas se habían salvado del incendio.

Habiendo sucedido así los hechos, es por lo que los familiares no tienen ningún documento oficial que los acredite como herederos y para justificar sus demandas, sólo cuentan con las cartas que René Dupé enviaba a su cuñado, el negociante en Nantes Pierre Godais, rindiendole cuentas de la situación de los negocios y de las operaciones que realizaba.

Dadas estas circunstancias y que las cosas se iban tranquilizando con el paso de los años, es por lo que los familiares deciden hacer la "declaración de herederos". Su fin es conseguir del Gobierno que les de a conocer en que "Deposito" están las Actas Públicas de la colonia; ya que les habian asegurado que en su momento fueron enviadas a Francia, con todo lo que se pudo salvar del desastre general.

Con estos documentos podrían demostrar que Dupé había comprado a Conette de Montaran en junio de 1790, una propiedad cafetera en la zona de "Plaisannu", cercana a El Cabo. La adquirió sin "negros", ni animales, por 200.000 libras, pagaderas en tres años y la pensaba llamar "Proprieté Dupé".

Conette de Montaran reclamó por aquellas fechas las 200.000 libras de la colonia, que eran 133.335 de Francia, signadas en una letra de adquisición, firmada por Dupé en noviembre de 1792 donde también decía que sólo tenía esa deuda.

En un principio los herederos ignoraban lo que había sucedido después, y cual era el activo de la fortuna que podían reclamar. Pero empiezan a aparecer papeles y se aclara que René Dupé vendió en 1790 su propiedad cafetera por el precio de 300.000 libras de la colonia, que equivalian a 200.000 de Francia, al señor Breuil, entonces panadero en el Cabo. Este señor era por las fechas en que se gestiona la herencia, empleado del gobierno francés en el Consulado de Filadelfia.

Por el mismo tiempo en que René Dupé realizó este negocio, también vendió al notario de El Cabo, señor Parré, otra propiedad cafetera de nombre "Veron", reservandose los "negros" y los animales que pensaba llevar a la propiedad que había comprado a Conette de Montaran. La venta de esta finca se realizó por 120.000 libras de la colonia, que eran 80.000 de Francia. El comprador también era en esos momentos empleado del Consulado francés en Filadelfia.

Según la documentación que iban consiguiendo, quedaba fuera de dudas que ninguno de estos dos señores - Breuil y Parré- habían pagado el dinero estipulado por la compra de las dos fincas, sumando en total 420.000 libras de la colonia y 280.000 de Francia.

Además el 9 de enero de 1792, René Dupé había escrito a sus familiares en Francia, que de las 500.000 libras que tenía colocadas en propiedades, difícilmente podía sacar más de las 420.000 que ya había conseguido, dadas las circunstancias de descorcierto y enfrentamientos que se estaban dando entre los distintos grupos de la colonia.

Pero de todo esto, los herederos no pueden presentar documentos, porque las Actas Públicas, o se habían quemado en el incendio del cabo, o el Gobierno las había archivado y ellos no sabían donde estaban. Es la razón por la que piden que se lo den a conocer y así poder consultarlas. 